OPEN ACCESS

Edited by:

Mark Andrew Lawrence, Deakin University, Australia

Reviewed by:

Kelly Shanene Fielding,

The University of

Queensland, Australia

Irana W. Hawkins,

Walden University, United States

${ }^{*}$ Correspondence:

Gary J. Pickering

gpickering@brocku.ca

Specialty section:

This article was submitted to

Nutrition and Sustainable Diets,

a section of the journa

Frontiers in Sustainable Food Systems

Received: 19 February 2020

Accepted: 07 July 2020

Published: 14 August 2020

Citation:

Ruzgys S and Pickering GJ (2020) Perceptions of Cultured Meat Among Youth and Messaging Strategies. Front. Sustain. Food Syst. 4:122 doi: 10.3389/fsufs.2020.00122

\section{Perceptions of Cultured Meat Among Youth and Messaging Strategies}

\author{
Shannon Ruzgys ${ }^{1}$ and Gary J. Pickering ${ }^{1,2,3,4 *}$ \\ ${ }^{1}$ Department of Psychology, Brock University, St. Catharines, ON, Canada, ${ }^{2}$ Department of Biological Sciences, Brock \\ University, St. Catharines, ON, Canada, ${ }^{3}$ Environmental Sustainability Research Centre, Brock University, St. Catharines, ON, \\ Canada, ${ }^{4}$ Sustainability Research Centre, The University of the Sunshine Coast, Sippy Downs, QLD, Australia
}

Cultured or "clean" meat (CM) is arguably a more ethical and environmentally sustainable alternative to farmed meat, but several potential psychological barriers exist to its acceptance in the marketplace. The perceptions of youth, as a specific consumer cohort, have not been reported to date despite young adults having more flexible dietary habits and being more likely to avoid red meat because of animal welfare and environmental concerns. Thus, youth represent a demographic that may be more accepting of $\mathrm{CM}$ and for whom the pro-environmental consequences of early adoption may be realized across an entire lifespan. In this study of college-aged Canadians (mean $=20$ years), we examined perceptions of CM (mixed methods) and assessed the effects of educational messaging about its benefits and then naturalness framing on intention to consume it (within subjects quantitative experimental design). Results show that youth believe CM to be unnatural, ethical, and environmentally friendly, and that taste is an important element of acceptance. Linear regression showed that food disgust was a significant predictor for both intent to incorporate CM into regular diet and completely replace meat/meat substitutes with $\mathrm{CM}$. In both instances, increasing food disgust was associated with lower behavioral intent. Environmental values were also a predictor for completely replacing meat/meat substitutes with $\mathrm{CM}$, where it positively affected intent and showed a similar effect size to food disgust. Both messaging on the benefits of $\mathrm{CM}$ and naturalness framing increased intent to consume it across all three measures and by a similar magnitude $[p(F)<0.05]$. These findings provide timely and actionable information for both $\mathrm{CM}$ producers and marketers and contribute to scholarship on the role of values and psychological traits in sustainable food choices.

Keywords: cultured meat, clean meat, naturalness, consumer acceptance, food disgust, framing, young adults

\section{INTRODUCTION}

Cultured meat $(\mathrm{CM})$ is poised to disrupt the meat industry, holding much promise as a sustainable and alternative protein to that sourced from the traditional intensive animal agriculture system (Tuomisto and Teixeira de Mattos, 2011). However, for this potential to be realized, a comprehensive understanding of how it is perceived by consumers and what the barriers are to its acceptance is needed (Siegrist et al., 2018). 
Youth are a key demographic to consider in this context, as their habitual dietary behavior is more flexible (Whitelock and Ensaff, 2018) and the environmental impact of their food choices can be realized over a longer time span compared with older individuals. To date there has been limited consideration regarding young adults' perceptions of and barriers to adopting $\mathrm{CM}$, and how these factors can be incorporated into effective messaging strategies. These knowledge gaps inform the current study.

A preponderance of literature indicates that climate change represents an existential threat to human civilization and that sweeping and immediate changes must be made across sectors in order to prevent the most devastating effects of climate change; "business as usual" is no longer a tenable option (Masson-Delmotte et al., 2018). Approximately $18 \%$ of global greenhouse gas (GHG) emissions can be attributed to animal agriculture (Steinfeld et al., 2006), making it one of the greatest contributors to climate change (Steinfeld et al., 2006). Aside from significant GHG emissions, livestock production is also responsible for large amounts of deforestation primarily to create crop fields for livestock feed, significant water use and water quality degradation, and strain on the global nitrogen cycle (Steinfeld et al., 2006; Roos et al., 2013; Westhoek et al., 2014). In the case of the global nitrogen cycle, evidence suggests that a planetary boundary has already been exceeded (Stevens, 2019). The negative environmental impacts of animal agriculture may worsen over the next several years, as the rate of meat consumption in developing countries continues to grow rapidly (Delgado, 2003; FAO, 2006; Allievi et al., 2015). At the level of the consumer, awareness of these environmental impacts of meat production and consumption appears surprisingly low (Stea and Pickering, 2018), and even when consumers are aware, most seem unwilling to remove meat from their diets (Hartmann and Siegrist, 2017).

The market for meat substitutes in western nations is increasing and is projected to continue to grow globally over coming years (Fortune Business Insights, 2019). In addition to an increase in the number of individuals adopting vegan and vegetarian lifestyles in western countries, meat substitutes are also finding increasing favor among meat eaters who want to engage in more ethical, environmentally friendly, and healthy food choices (Bourassa, 2019). However, even greater uptake of plant-based alternatives, particularly amongst non-, light- and medium-users, is limited mainly by negative beliefs about their sensory appeal (Hoek et al., 2011). These challenges, coupled with the need for environmentally sustainable food systems, provide opportunities for alternative approaches to traditional intensive animal agriculture.

$\mathrm{CM}$ offers a potential alternative protein source both for individuals who avoid meat because of ethical, religious, or environmental concerns associated with industrialized production methods, and for current meat-eaters who desire a more environmentally sustainable source or reject meat substitutes due to taste concerns. It is a product of cellular agriculture produced using tissue-engineering technology where the muscle cells of animals are cultured in a bio-reactor

Abbreviations: CM, Cultured meat; GHG, Greenhouse gas emissions. independent from the animal (Bhat et al., 2017). By comparison, fermentation-based cellular agriculture does not use any tissue from a living animal; instead, edible products are engineered by fermentation using bacteria, algae or yeast that have typically been genetically modified through the addition of recombinant DNA (Stephens et al., 2018). The culture media that is used in producing $\mathrm{CM}$ includes fetal animal serum, which contains a range of growth factors, hormones, vitamins, and other components necessary to support cell growth. Antibiotics are also sometimes added to the cells in culture to prevent infection (Stephens et al., 2018). A scaffold is then used to facilitate cell adhesion, proliferation, and tissue development in order to form a 3D skeletal muscle. A review of the technological considerations around CM manufacture-including the wider benefits and objections-can be found in Bhat et al. (2017).

In addition to the potential ethical benefits of a slaughter free harvest, most literature concludes that CM is significantly better for the environment on multiple fronts. For instance, Tuomisto and Teixeira de Mattos (2011) compared $1,000 \mathrm{~kg}$ of beef, sheep, pork, and poultry to $1,000 \mathrm{~kg}$ of $\mathrm{CM}$, and calculated CM production uses 7-45\% less energy, 99\% less land, $82-96 \%$ less water, and emits $78-96 \%$ less GHG. While most existent literature agrees that $\mathrm{CM}$ is environmentally much more sustainable, Lynch and Pierrehumbert (2019) have recently challenged the assumption that CM is climatically better than cattle, arguing that its relative GHG emissions depend on the specific production system used and the availability of decarbonized energy generation. There are also several other potential drawbacks to $\mathrm{CM}$ as a whole. The animal-derived serums currently required in the cell growth phase of production are expensive, and their animal origins may be a barrier for some consumers (Stephens et al., 2018). The health impacts of cultured red meat must also be considered, given that consumption of red meat is linked to coronary heart disease, cancer, and mortality risk (Ferguson, 2010; Zhong et al., 2020). However, $\mathrm{CM}$ also offers the potential during production to engineer changes at the cellular and tissue levels, which may extend in the future to reducing or altering molecules associated with these health impacts (Post, 2012). Regardless, some consumers appear less accepting of the risks linked with meat consumption, including colon cancer, when the source is considered unnatural (e.g., cultured) as opposed to traditionally farmed (Siegrist and Sütterlin, 2017). Despite these challenges, recent years have seen considerable interest and investment in start-up enterprises seeking to both scale-up CM to commercial production levels and bring down associated costs. In recognition that $\mathrm{CM}$ will likely be "on the shelves" sooner rather than later, the United States Department of Agriculture and Food and Drug Administration approved CM in late 2018, and announced that they would jointly oversee its production in order to assure it could be safely sold to consumers across the USA (Commissioner, 2018), reflecting similar regulatory activity in other countries. CM appears well on its way to becoming a commercially available alternative to farmed meat.

Despite the environmental and animal welfare benefits of $\mathrm{CM}$, several potential barriers to consumer acceptance have been identified. Two of these are often associated with acceptance 
of new foods more generally; food disgust and food neophobia (Hoek et al., 2011; Siegrist et al., 2018). Disgust is a natural biological response that can lead to avoidance of some foods, while food neophobia is a personal trait that describes one's willingness to try new food. Egolf et al. (2018) reported that Swiss adults with higher levels of food disgust tend to be pickier eaters and are less likely to try new foods. Also in a Swiss population, Siegrist et al. (2018) found that descriptions of CM evoked high levels of reported disgust from participants and negatively impacted their perceptions of it. Similarly, a recent study with US participants by Wilks et al. (2019) found that food disgust and food neophobia were very strong predictors of absolute opposition to CM. In addition, food neophobia is a significant predictor of willingness to try new foods generally (Tuorila et al., 2001) and food neophobes tend to make more negative evaluations and have different expectations toward unfamiliar foods (Raudenbush and Frank, 1999). However, food neophobia does not seem to be associated with consumers' willingness to try products created through new food technologies, such as those involving genetically modified organisms (Siegrist, 2008).

The greatest psychological barrier to consumption of $\mathrm{CM}$ may be its perceived unnaturalness, with several studies across multiple countries citing this as a significant concern for potential consumers (Laestadius and Caldwell, 2015; Verbeke et al., 2015a; Siegrist et al., 2018). When defining what makes food natural, consumers often state that the production process should involve minimal processing and follow traditional production methods (Román et al., 2017). CM is produced using tissue engineering technology which appears to be perceived as inherently unnatural, and when consumers view a food technology as unnatural they are more likely to believe that technology is risky and are less accepting of its possible benefits (Ronteltap et al., 2016).

While consumers perceive $\mathrm{CM}$ to be unnatural which may impact their intent to eat it, it is less clear to what extent this belief is susceptible to change through consumer education on the benefits of CM or through how the product is framed in promotion and messaging activities. These considerations have been given some preliminary attention in both peer reviewed (Verbeke et al., 2015b; Siegrist and Sütterlin, 2017) and non-peer reviewed (Anderson and Bryant, 2018) media in recent years. Both intent to reduce intake of farmed red meat in Canada (Stea and Pickering, 2018) and willingness to consume $\mathrm{CM}$ in Belgium (Verbeke et al., 2015b) increase when information alone is provided on the environmental issues associated with traditional meat production. Message framing also offers the potential to elicit greater pro-environmental behavior across a range of activities, including food consumption (Smith and Petty, 1996; Gifford and Bernard, 2006; Goldstein et al., 2008). There are many ways in which framing can be conceptualized and operationalized. For instance, equivalency framing uses different but logically equivalent words or phrases to alter thinking or preferences (e.g., $95 \%$ fat-free or $5 \%$ fat), whereas emphasis framing-used in the current study-stresses a subset of relevant considerations (Druckman, 2001). Siegrist and Sütterlin (2017) have noted that Swiss and European Union consumers rely heavily on symbolic information when evaluating foods, particularly information that positions them as more natural, such as "organic" and "non-GMO" (examples of emphasis framing). Given these considerations, we expect that behavioral intent toward CM may be enhanced through both consumer education on its benefits and messaging that is framed around naturalness.

The main objectives of the present research are to:

1. Determine the opinions and beliefs held by youth toward CM.

2. Determine the relationship between willingness to consume CM and food neophobia, food disgust (H2), and environmental values (as assessed by the shortened version Whitmarsh, 2011 of the New Ecological Paradigm Dunlap and Van Liere, 1978).

3. Determine the impact on behavioral intent of educational messaging around the general benefits of $\mathrm{CM}$ and framing it as natural; specifically, willingness to try $\mathrm{CM}$, willingness to incorporate $\mathrm{CM}$ into regular diet, and willingness to completely replace farmed meat/meat alternatives with $\mathrm{CM}$ in regular diet.

Our hypotheses are:

1. Food neophobia will be negatively associated with willingness to consume $\mathrm{CM}\left(\mathrm{H}_{1}\right)$.

2. Food disgust will be negatively associated with willingness to consume $\mathrm{CM}\left(\mathrm{H}_{2}\right)$.

3. Given that adults with high environmental values show greater preference for CM than those with lower values (Slade, 2018), we expect that the same relationship will hold for youth $\left(\mathrm{H}_{3}\right)$.

4. Youth will show greater willingness to eat $\mathrm{CM}$ in response to both educational information and naturalness framing $\left(\mathrm{H}_{4}\right)$.

Youth has been chosen as the demographic for this study for several reasons. There is a lack of prior research on CM and youth specifically, and young adults have more flexible dietary habits than older individuals and are more likely to eat meatless meals and avoid red meat due to animal welfare and environmental concerns (Ruby, 2012; Whitelock and Ensaff, 2018). Food choice can be a means of enacting one's identity and communicating it to others, and the transition into adulthood provides an opportunity for young adults to explore different identities as eaters (Devine, 2005), including the adoption of diets and products that were not part of their upbringing. Taken together, these considerations suggest that they are a demographic that could be more accepting of CM. From an industry perspective, youth may be a more profitable market segment if $\mathrm{CM}$ is incorporated into habitual diet across the lifespan, in addition to the long-term potential environmental impact. Our study builds on existent literature by focusing on the perception and attitudes of young adults and examines for the first time the role of food disgust and food neophobia in moderating these percepts in youth. Additionally, it employs experimental manipulation of educational information and naturalness messaging to capture quantitatively behavioral intent toward CM. Our findings will inform considerations around the marketing and viability of 
$\mathrm{CM}$ and contribute to the development of a more sustainable food system.

\section{MATERIALS AND METHODS}

\section{Recruitment and Sample Description}

A convenience sample of 214 Canadians college-aged participants was recruited between October-December, 2018, through Brock University's SONA (research trial recruitment) system, posters, and social media posts. Brock University has a student population of 19,100 . The title of the project communicated to prospective participants was "Perceptions of cultured meat and optimization of messaging," with the following study description provided: "The purpose of this study is to understand the attitudes of college-aged students hold toward cultured meat." Eligibility criteria required that participants be 18-30 years of age and Canadian citizens or permanent residents. Respondents from Brock were offered research credit as an incentive that could be used toward course credit in one of several classes. The median time of completion for the online survey (32 questions) was $9.9 \mathrm{~min}$, and 14 participants were removed due to incomplete data leaving 200 useable responses. Participants used an URL link to access the survey which was administered using the Qualtrics ${ }^{\mathrm{TM}}$ platform (2015, Provo, Utah, US). Ethics clearance was granted by the Brock University Research Ethics Board (File \#18-036). All participants gave written informed consent in accordance with the Declaration of Helsinki.

\section{Demographics, Meat Consumption, and Environmental Values}

Demographic information was collected using measures adapted form Morris and Pickering (2019), including citizenship, age, ethnicity, gender, political orientation, and importance of religion. Participants were then asked to indicate on average how many times a month they consumed meat, using response categories which ranged from 0 to $80+$. If participants indicated that they ate meat zero times a month they were then prompted to indicate what they most closely identified as (pescetarian, vegetarian, vegan-categories adapted from Mayo Clinic, 2019) followed by a check-all-that-apply scale where they provided their reasoning for not consuming meat (ethical concerns, health reasons, environmental concerns, allergies, do not enjoy the taste, social pressures; adapted from Rozin et al., 1997). Other participants were asked to select all of the types of meat that they regularly consumed on a check-all-that-apply scale (beef, pork, poultry, fish/other seafood, deer/rabbit, other). Participants then completed a shortened version (Whitmarsh, 2011) of the New Ecological Paradigm (NEP; Dunlap and Van Liere, 1978) which measures environmental values, with responses to indicator statements captured on 5-point Likert scales (Supplementary Materials).

\section{Attitudes and Behavioral Barriers}

Using a mixed-methods approach, participants' opinions of CM were examined. First, current knowledge about CM was assessed by asking participants how much they know about the product, with response options on a five-point Likert scale ranging from nothing at all to a great deal. Participants were then given the following passage briefly describing CM, adapted from Siegrist et al. (2018): Cultured meat ("lab-grown meat") is produced using tissue-engineering technology where animals cells are grown in a controlled environment outside of and independently of the animal, which results in no animals being harmed or killed in the process. The end product is comparable to traditional meat with regard to texture and taste. Our adaptation was mainly to adjust the wording away from the ground beef focus of Siegrist et al. (2018) to make the passage more generalizable to all CM.

After this passage participants were asked an open-ended question about their opinion on consuming CM. Content analysis was then applied to these responses using NVivo12 and following the general approach of Morris and Pickering (2019). Individual responses were read by both authors, and tentative themes determined. During an iterative process these theme categories were further refined. A codebook was then developed that articulated the criteria for binning each response into a thematic category (refer Supplementary Materials). Individual opinions that reflected multiple concepts (e.g., both Animal welfare and Health) were counted in each of the relevant theme categories. Counts for each category were then made and expressed as a percentage of total responses. Respondents were then asked five questions, based on common opinions and proposed benefits identified in other studies and populations (Verbeke et al., 2015a; Bhat et al., 2017), which they responded to on a 5-point Likert scale: How healthy do you think cultured meat is? How natural do you think cultured meat is? How environmentally friendly do you think cultured meat is? How ethical do you think cultured meat is? How disgusting do you think cultured meat is? Next, participants rated how strongly they agreed with four statements on potential barriers adapted from Verbeke et al. (2015b) (5-point Likert scale, ranging from strongly agree to strongly disagree): Cultured meat wouldn't taste the same as farmed meat; I would not be willing to spend more money on cultured meat; science does not understand enough about cultured meat to sell it as a viable alternative; I do not see any personal benefits to eating cultured meat.

At the end of the survey, after the messaging treatments below, we administered the shortened Food Disgust Scale (Hartmann and Siegrist, 2018), as validated in English by Egolf et al. (2019) and Thibodeau et al. (in press) and the Food Neophobia Scale (Pliner and Hobden, 1992; 5-point Likert scale-strongly agree to strongly disagree) to further investigate potential psychological barriers to CM consumption (Supplementary Materials).

\section{Messaging Treatments}

Participants initially answered three questions about their intention to consume $\mathrm{CM}$ on a 7-point Likert scale, ranging from extremely unlikely to extremely likely: (1) If readily available, how likely is it that you would try cultured meat?; (2) If readily available, how likely is it that you would incorporate cultured meat into your regular diet? The final question differed depending on participants' previously indicated meat consumption habits. 
Those who indicated they ate meat zero times a month answered (3) If readily available, how likely is it that you would completely replace meat alternatives with cultured meat in your regular diet? Whereas, those who ate meat one or more times a month answered (4) If readily available, how likely is it that you would completely replace farmed meat with cultured meat in your regular diet?

Participants were then shown five statements which outlined the general potential benefits of CM ("educational information") adapted from Bhat et al. (2017) and Stephens et al. (2018): Cultured meat is produced using tissue-engineering technology and does not involve the traditional methods of rearing and slaughtering animals; Cultured meat could greatly reduce the number of food-borne illnesses such as salmonella; There is no animal suffering involved in the production of cultured meat; Cultured meat is produced in a lab and therefore does not require nearly as much land as traditional animal agriculture; Cultured meat could be used to combat starvation and malnutrition in third world countries. After reading these five statements, participants again indicated their intention to consume $\mathrm{CM}$ by responding to the three questions detailed above on 7-point Likert scales.

Participants were then shown five statements that framed CM as natural, adapted from Figure 2 of the systematic review on food naturalness perception of Román et al. (2017): Cultured meat can be enhanced to contain healthy vitamins and reduce the amount of unhealthy fats; Cultured meat contains no artificial colors/flavors, preservatives, or additives; No chemicals, hormones, or pesticides are used in the production of cultured meat; Cultured meat is free of all GMOs (genetically modified organisms); Cultured meat could reduce the carbon footprint of the animal agriculture industry and reduce its greenhouse gas emissions by up to $90 \%$. After reading these five statements, participants again indicated their intention to consume $\mathrm{CM}$ by responding to the three questions detailed above on 7-point Likert scales.
This empirical research design involves experimental manipulation whereby the independent variable(s) (the type of information/messaging the participants receive) are systematically varied to examine the effect on the dependent variable(s) (intent to consume CM) (Ruble, 2017). It is an approach that is common in several academic disciplines, including communications and psychology, and has been used to examine how information or its framing influence pro-environmental behaviors and beliefs in recent studies (e.g., Stea and Pickering, 2018; Munoz-Carrier et al., 2020). While we acknowledge that the accuracy of some of the statements included in the "educational information" and "naturalness framing" treatments may be debatable, we believe they have good ecologically validity with respect to how the CM industry is positioning and some media is reporting on these products (Goodwin and Shoulders, 2013), and they are informed by existent peer-reviewed literature (for reviews, see Bhat et al., 2017 and Bryant and Barnett, 2018).

The survey was field-tested with 10 college-aged volunteers to assess question comprehension and clarity, and survey flow and logistics. No substantive issues were identified, and two (minor) operational changes were made to the final survey before launching.

\section{RESULTS}

\section{Sample Characteristics}

The average age of our 200 respondents was 20.4 years, with $79.5 \%$ identifying as female, $20 \%$ male, and $0.5 \%$ as other. With respect to political identification, $13 \%$ identified as conservative, $40 \%$ identified as neutral, and $48 \%$ identified as liberal. For meat consumption, $12 \%$ indicated that they consumed meat zero times a month, $68 \%$ indicated that they consumed meat 1-30 times a month, and $21 \%$ indicated that they consumed meat 31 or more times a month. In response to the question "How much

TABLE 1 | Key themes from the open response question "What is your opinion about the consumption of cultured meat?"

\begin{tabular}{|c|c|c|c|}
\hline $\begin{array}{l}\text { Key themes in } \\
\text { responses }\end{array}$ & Count & $\%$ & Examples \\
\hline Animal welfare & 48 & $25 \%$ & "I think it's a great alternative to the killing of animals" \\
\hline Environment & 33 & $17 \%$ & $\begin{array}{l}\text { "I would } 100 \% \text { try it, I believe it will be very beneficial to the environment and the future of the earth"; "It's } \\
\text { not good for you or the environment" }\end{array}$ \\
\hline Naturalness & 31 & $16 \%$ & "I think it's unnatural ..." \\
\hline Health & 19 & $8 \%$ & "Should be a good substitute, but only if it is also high in nutritional value" \\
\hline Taste & 17 & $9 \%$ & "I would very much so like to sample this type of meat to test the difference between the two" \\
\hline Cost & 5 & $3 \%$ & "I think it seems like a good idea but I think it will end up costing too much in comparison to actual meat" \\
\hline Want more information & 16 & $8 \%$ & $\begin{array}{l}\text { "I think it sounds like a good idea, but further research on the effects of it on human health, short term } \\
\text { and long term need to be studied"; "Would prefer to know long-term effects of consuming GMO's like } \\
\text { this before turning to it as my only meat source" }\end{array}$ \\
\hline Other & 29 & $15 \%$ & $\begin{array}{l}\text { "It is important for us to leave the ecosystems of bacteria fungi and plant cells in order for it to sustain, } \\
\text { reproduce, and support itself" }\end{array}$ \\
\hline Generally positive & 95 & $69 \%$ & "Interesting idea, very creative and potentially successful alternative to common meat" \\
\hline Generally negative & 42 & $31 \%$ & $\begin{array}{l}\text { "It seems rather disturbing to know that that is an option. It is something I never really knew existed. It is } \\
\text { definitely not something that I look out for when considering a food option on a menu or buying it in } \\
\text { store, nor do I think it ever will." }\end{array}$ \\
\hline
\end{tabular}




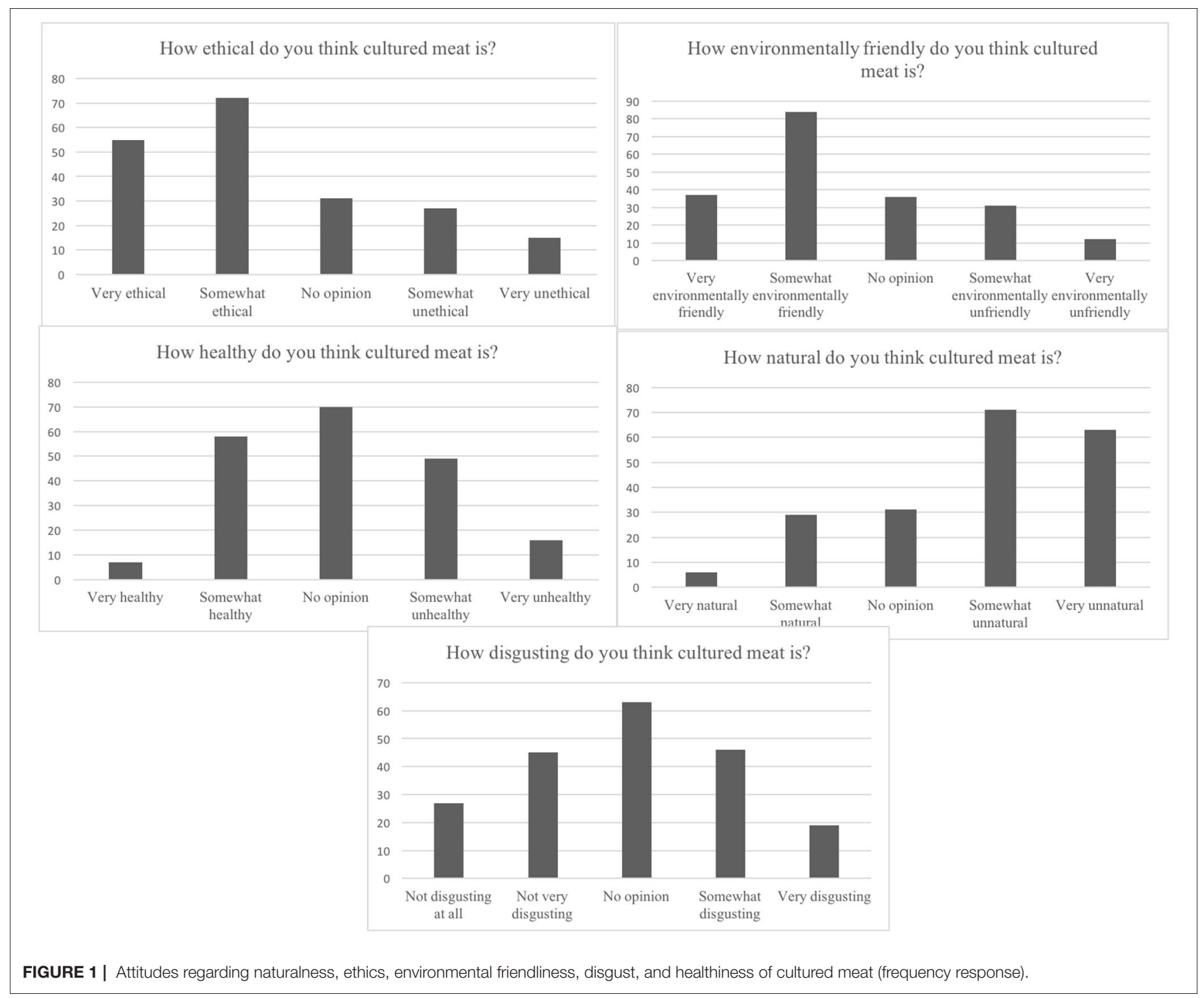

do you know about cultured meat?," $1 \%$ indicated they knew a great deal, $2 \%$ indicated they knew a lot, $16 \%$ indicated they knew a moderate amount, $36 \%$ indicated they knew a little, and $46 \%$ indicated they knew nothing at all.

\section{Opinions and Barriers}

Participants were asked an open response question about their opinion of the consumption of CM. The most common themes to emerge were the possible benefits CM could have for animal welfare and the environment, and concerns about the naturalness of the product (Table 1). Of the $71 \%$ of responses that could be clearly identified as either generally positive or generally negative, $69 \%$ were positive while only $31 \%$ were negative.

Participants were then asked how healthy, natural, environmentally friendly, ethical, and disgusting they thought $\mathrm{CM}$ was (Figure 1). The majority indicated that they found $\mathrm{CM}$ to be somewhat or very unnatural $(67 \%)$, somewhat or very ethical $64 \%$, and somewhat or very environmentally friendly
(61\%). There was no majority agreement on how disgusting CM was regarded, with $36 \%$ finding it not disgusting at all or not very disgusting, 33\% rating it somewhat or very disgusting and 32\% having no opinion. The distribution was also very similar for opinions on healthiness.

With respect to response to statements that capture consumer objections identified by Verbeke et al. (2015b) (Figure 2), "I do not see any personal benefits to eating CM" elicited the most disagreement with $59 \%$ indicating they moderately or strongly disagreed. Responses to "I would not be willing to spend more money on CM" were the most polarized with $45 \%$ stating they moderately or strongly agreed and $40 \%$ stating that they moderately or strongly disagreed.

The statement "Science does not understand enough about $\mathrm{CM}$ to sell it as a viable alternative" had the largest proportion of respondents indicating they neither agreed nor disagreed (36\%), with the remaining responses split relatively evenly between moderate or strong agreement (34\%) and moderate or 
Cultured meat wouldn't taste the same as farmed meat.

Science does not understand enough about cultured meat to sell it as a viable alternative.

I would not be willing to spend more money on cultured meat.

I do not see any personal benefits to eating cultured meat.

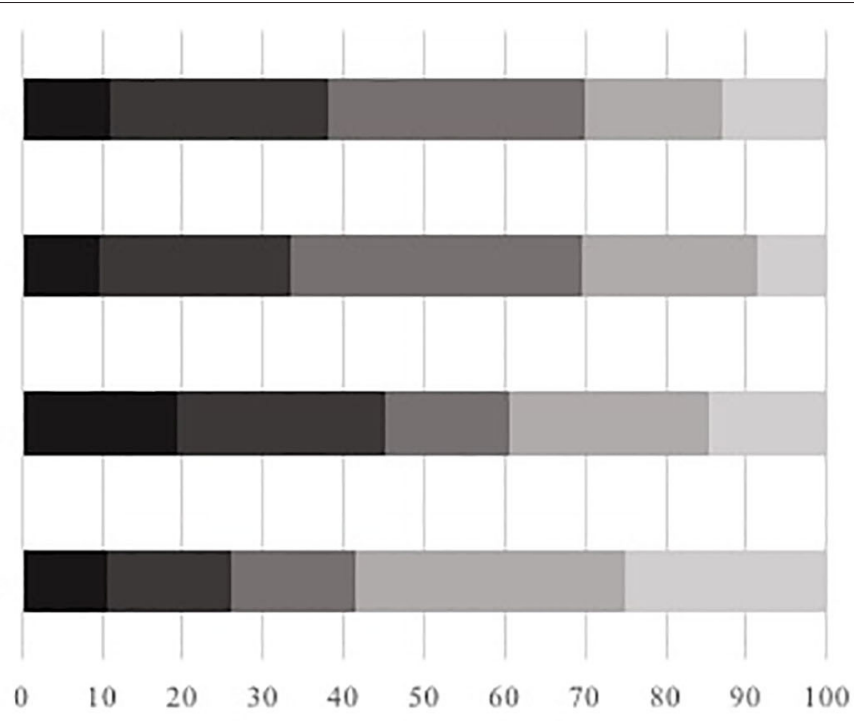

QStrongly agree Moderately agree $\quad$ Neitheragree nor disagree Moderately disagree $\square$ Strongly disagree

FIGURE 2 | Potential barriers to consumption of cultured meat. Data show level of agreement with four statements adapted from Verbeke et al. (2015b) (\% of responses).

TABLE 2 | Predictors (linear regression) of initial intent to try culture meat, incorporate it into regular diet, and completely replace meat/meat substitutes with it.

\begin{tabular}{llrrr}
\hline & & $\mathbf{t}$ & $\mathbf{p ( t )}$ & Standardized coefficient \\
\hline Intent to try & Food disgust & -1.93 & 0.06 & -0.15 \\
& Food neophobia & -1.03 & 0.31 & -0.08 \\
& Environmental values & 0.19 & 0.85 & 0.01 \\
Intent to incorporate & Food disgust & -2.66 & 0.01 & -0.21 \\
into regular diet & Food neophobia & -0.93 & 0.36 & -0.07 \\
& Environmental values & 0.71 & 0.48 & -0.05 \\
Intent to completely & Food disgust & -2.10 & 0.04 & -0.01 \\
replace meat/meat & Food neophobia & -0.09 & 0.93 & 0.16 \\
substitutes & Environmental values & 2.22 & 0.03 & \\
\hline
\end{tabular}

strong disagreement (31\%). Responses to “CM wouldn't taste the same as farmed meat" were relatively evenly distributed between moderate or strong agreement (38\%), moderate or strong disagreement (30\%), and neither agreement nor disagreement (32\%).

\section{Behavioral Intent and Response to Messaging}

Prior to message exposure participants were asked to indicate their intention to try $\mathrm{CM}$, incorporate $\mathrm{CM}$ into their regular diets, and replace farmed meat/meat alternatives with $\mathrm{CM}$ in their regular diets. We ran a linear regression for each intention to examine the influence of food disgust, food neophobia, and environmental values (NEP score). Age, gender, and political orientation were included in the initial regressions, but as they did not affect the results for the main effects that we were investigating (food disgust, food neophobia, environmental values), they were not included in the final models (data not shown). As shown in Table 2, food disgust was a significant predictor for both intent to incorporate $\mathrm{CM}$ into regular diet and completely replace meat/meat substitutes with CM. In both instances, increasing food disgust associated with lower behavioral intent. Increasing NEP score also predicted intent to completely replace meat/meat substitutes with CM, and showed a similar effect size to food disgust. There was no association found between participants' food disgust scores and how disgusting they rated $\mathrm{CM}(r=0.08, p=0.24)$. The distributions of the food neophobia, NEP and food disgust scores are given in Supplementary Materials.

Behavioral intent was assessed again after exposure to each of the messages; the first message highlighted the general benefits of $\mathrm{CM}$ and the second framed CM as natural (Figure 3).

Additionally, participants were asked How natural do you think cultured meat is? both before and after messaging as a validity check of the naturalness frame. Overall, participants 


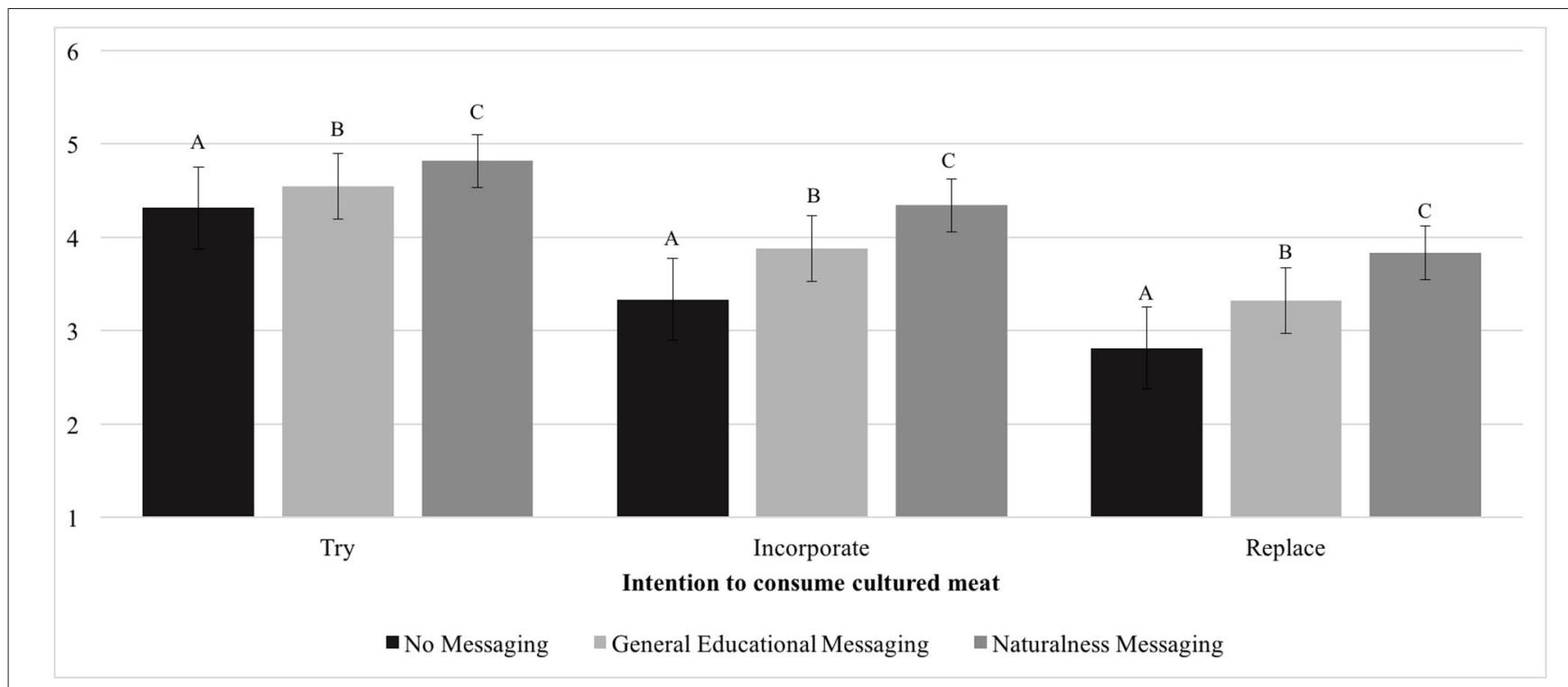

FIGURE 3 | Intention to try cultured meat, incorporate cultured meat into regular diet, and replace farmed meat/meat alternatives with cultured meat in regular diet across messaging treatments. Data shown are average responses from 7-point Likert scale ( 1 = "extremely unlikely" $7=$ "extremely likely") \pm standard error. A, B, and $\mathrm{C}$ represent significant differences between the messaging treatments (Bonferroni 0.05).

indicated they found $\mathrm{CM}$ to be more natural after message exposure $\left[t_{(198)}=5.03, p<0.001\right]$, suggesting the intended naturalness construct was elicited by the messaging.

Three one-way within subjects ANOVAs were conducted to examine changes in intent to try, incorporate, or replace with cultured meat across the three messaging treatments (no messaging, educational messaging, educational plus naturalness messaging), followed by Bonferroni post-hoc tests. GreenhouseGeisser corrections were also applied to all three ANOVAs to adjust for violation of sphericity. $F$-values were significant for all of the dependent variables; try $\left[F_{(1.76,199)}=16.57, p<\right.$ $0.001]$, incorporate $\left[F_{(1.65,199)}=42.25, p<0.001\right]$, and replace $\left[F_{(1.71,199)}=49.85, p<0.001\right]$, with Bonferroni results showing that each sequential message elicited greater behavioral intent for each of the dependent variables. Specifically, when participants were given information about the general benefits of CM there was a $5 \%$ increase in intent to try CM, a $16 \%$ increase in intent to incorporate $\mathrm{CM}$ into their regular diets, and an $18 \%$ increase in intent to replace farmed meat/meat alternatives with $\mathrm{CM}$. When CM was then framed as natural participants reported an additional $6 \%$ increase in intent to try $\mathrm{CM}$, a $12 \%$ increase in intent to incorporate $\mathrm{CM}$ into their regular diets, and a $15 \%$ increase in intent to replace farmed meat/meat alternatives with CM.

\section{Moderating Factors and Examination of Group Differences}

A multiple regression was run to test the effect of environmental values (New Ecological Paradigm), food neophobia (Food Neophobia Scale), and food disgust (Food Disgust Scale) on change in intention to consume CM after messaging. Change in intent was quantified by subtracting each participant's score after the naturalness messaging from their score before any messaging.
Three regressions were run with change in intention to try CM, change in intention to incorporate CM into regular diet, and change in intention to completely replace farmed meat/meat alternatives with $\mathrm{CM}$ as the dependent variables. There were no significant effects, for try $\left[F_{(4,197)}=0.56, p=0.69\right]$, incorporate $\left[F_{(4,197)}=2.16, p=0.08\right]$, or replace $\left[F_{(4,197)}=0.60, p=0.66\right]$, suggesting that environmental values, level of food disgust, and level of food neophobia did not influence response to messaging.

We also examined whether there were any group differences between participants who responded positively to the messaging (showed increase in intent) and those who did not (no change in intent) for willingness to try, incorporate, and replace. The groups that were compared were males $(n=40)$ vs. females $(n=$ $159)$, vegetarians/vegans $(n=23)$ vs. meat eaters $(n=177)$, low meat consumers ( $0-30$ times a month; $n=159)$ vs. high meat consumers $(31+$ times a month; $n=41)$, low environmental values (NEP score of 3.99 or less; $n=80$ ) vs. high environmental values (NEP score of 4.00 or more; $n=120$ ), those who stated religion was an important aspect of their lives $(n=115)$ vs. those who stated that it was not $(n=85)$, and liberals $(n=96)$ vs. conservatives $(n=25)$. Chi-squared tests did not reveal differences between any of these groups for any of the three intent measures $[p(\chi 2)<0.05]$. In some instances, the analyses may have been underpowered due to small group sizes (refer Supplementary Materials).

\section{DISCUSSION}

\section{Perceptions, Behavioral Intent and Implications}

This study is the first known to us that reports on young adults' opinions of $\mathrm{CM}$ while also examining the effects of messaging on intention to consume it. Respondents see $\mathrm{CM}$ 
as promoting animal welfare, environmentally friendly, and unnatural, as evidenced from both open ended responses and targeted questions, consistent with previous reports on older cohorts (Laestadius and Caldwell, 2015; Verbeke et al., 2015a). Animal welfare was the most cited theme in the open-ended responses, and previous work with young adults has identified animal welfare concerns as a driver for eating less meat (reviewed in Ruby, 2012). Further research is encouraged to expand this finding and its potential for assisting in acceptance of CM. For instance, how appealing might $\mathrm{CM}$ be to ethical vegetarians (individuals who avoid meat due to moral consideration around animal welfare; Ruby, 2012), and to what extent might emphasis framing that stresses animal welfare benefits be an effective marketing strategy for some youth cohorts, including ethical vegetarians? Participants also indicated that an important factor when considering whether they would consume CM or not is whether it tastes the same as farmed meat, consistent with the report of van der Weele and Driessen (2019) in a Dutch cohort. This result provides some direction for CM producers with respect to optimizing their product and suggests that sensory and consumer testing should be critical components of the product development process in order to achieve market acceptance.

In contrast with Verbeke et al. (2015b), the majority of our participants disagreed with the statement "I do not see any personal benefits to eating CM." It is not clear what personal benefits respondents may envision. They may be related to reduced environmental impact-one of the greatest suggested benefits of CM (Bhat et al., 2017) — and/or to reduced concern about animal welfare. Participants who had higher than average environmental values (NEP score $>4$ ) were significantly more likely to disagree with the statement than those with a lower environmental values (NEP score $\leq 3.99)\left[\mathrm{X}^{2}(1, N=169)=\right.$ $5.20, p<0.05]$. Thus, it is possible that individuals with higher environmental values may view the lower environmental impact of CM as a personal benefit.

There was no relationship between intention to consume $\mathrm{CM}$ and food neophobia; thus we failed to find evidence to support $\mathrm{H}_{1}$. Previous research has found that people who score higher for food neophobia are less willing to eat meat substitutes (Hoek et al., 2011) and food neophobia has been associated with rejection of CM in an adult sample (Wilks et al., 2019). However, our result is consistent with previous findings that food neophobia does not impact consumers' willingness to try foods that have been created through new technologies (Siegrist, 2008). Our null result may have been influenced by our initial description of $\mathrm{CM}$ as having a comparable taste and texture to farmed meat, as these are two of the most important qualities for meat consumers (Grunert et al., 2004) and two of the most common objections to consuming meat substitutes (Hoek et al., 2011).

We found a negative relationship between food disgust and initial intention to consume CM, confirming $\mathrm{H}_{2}$ ("Food disgust will be negatively associated with willingness to consume") and consistent with the report of Siegrist et al. (2018) that descriptions of CM evoke high levels of reported disgust and negatively impact perceptions of it. However, we did not find a relationship between food disgust and intention to consume
$\mathrm{CM}$ after messaging, indicating that food disgust may not be a barrier to consumer acceptance of CM if effective messaging strategies can be employed. There was no relationship found between NEP scores and intention to consume CM; thus we failed to find evidence to support $\mathrm{H}_{3}$, contrary to previous findings that individuals with high environmental values have a stronger preference for CM (Slade, 2018). However, our sample had very high pro-environmental values, consistent with the wider Canadian population (Pickering, 2015), with an average NEP score of $4.0 \pm 0.6 \mathrm{SD}$. There may have been insufficient variation in responses to capture a relationship. Slade (2018) also found that men and liberals were more receptive to CM than woman and conservatives; however, we did not replicate these findings in our data. This may be attributable to our analyses being underpowered, as only 40 respondents were men and only 25 identified as conservative.

\section{Message Frame Effectiveness and Implications}

Educational messaging (Pickering et al., 2020) and message framing (Smith and Petty, 1996) can be effective tools in eliciting desired behavior, and consumers have shown increase in intent to consume products such as organic foods or CM when they are provided with information about their benefits or when they are framed positively (Gifford and Bernard, 2006; Siegrist and Sütterlin, 2017). Message framing has also been show to assist people in adopting pro-environmental behaviors more broadly (e.g., Goldstein et al., 2008; Stea and Pickering, 2018) and in overcoming cognitive and behavioral biases (Asensio and Delmas, 2016). In our study, both providing participants with information on the general benefits of $\mathrm{CM}$ and then framing it as natural increased intent to consume CM, confirming $\mathrm{H}_{4}$ ("Youth will show greater willingness to eat $\mathrm{CM}$ in response to both educational information and naturalness framing"). The effect of educational messaging stressing the benefits is perhaps not surprising, given that a significant minority of this cohort were unfamiliar with the product prior to the study commencing. The positive influence of naturalness framing is consistent with our finding that the majority of respondents considered CM to be unnatural prior to messaging, and agrees with predictions that could reasonably be drawn from earlier reports showing that perceived unnaturalness is a significant concern for adult consumers (Laestadius and Caldwell, 2015; Verbeke et al., 2015a; Siegrist et al., 2018). It is possible that alternative or complimentary framing approaches to naturalness could elicit even greater behavioral intent by youth toward adopting CM, and future research is encouraged in this area. For instance, socially normative framing (Hurlstone et al., 2014) or highlighting the negative elements of farmed meat rather than the benefits of CM may be worth investigating.

This information may be useful for marketing CM, as it shows that both informing consumers about the benefits of CM and framing it as natural can alter intention to eat the product. Perhaps most importantly, both types of messaging led to a significant increase in intent to try CM. The "mere exposure effect" shows that the more someone 
tastes a product, the greater the likelihood that will like it and incorporate it into their diet (Pliner, 1982). Thus, for such a novel product as $\mathrm{CM}$, marketing and promotional efforts that incorporate opportunities for customers to sample CMsuch as free tasting stations in supermarkets-may be beneficial in helping to transition people through to becoming regular consumers. However, this speculation assumes that the sensory characteristics of CM can meet or exceed customer expectations; that is, they must be similar to farmed meat. Indeed, a potentially valuable avenue of future research would be to determine empirically just how similar CM products need to be to their farmed meat equivalents in order to achieve market acceptance.

While our results provide support for the use of specific messaging types to increase behavioral intent, there is the question of what the most effective way is to deliver these messages to young adults. The media used by youth to receive marketing is very different than for many older adults. The internet provides an array of new and constantly evolving platforms for food companies to reach consumers, with young people the primary users (Montgomery and Chester, 2009). Using social media as a marketing tool can be a very effective way to spread product information to a large audience. For instance, in 2019 there were one billion active Instagram users in the world, and in the United States over half were between the ages of 18 and 29 years old (Statista, 2018). Social media sites such as Instagram are one of the most effective ways to target youth, and likely will be a more successful option for delivering CM messaging to them than the more traditional print, radio and TV media.

\section{Other Considerations and Limitations}

Our study specifically examined young adults for several reasons. Firstly, youth inherit our changing climate and are key actors in promoting sustainable lifestyles, adopting environmentallyfriendly practices and implementing adaption and mitigation projects (Youth Stats: Environment and Climate Change, 2015). They make up the majority of the population in several countries and their increasingly strong environmental awareness is a vital asset in climate change mitigation (Youth and Climate Change, 2010). Understanding their beliefs and motives around making more environmentally sustainable food choices is important if meaningful and lasting progress is to be made toward mitigating climate change (Pickering et al., in press). Additionally, young adults have more flexible dietary habits than older individuals (Whitelock and Ensaff, 2018), and those dietary habits that are established in childhood and adolescence tend to be stable into adulthood (Lake et al., 2006; Movassagh et al., 2017). Thus, marketing efforts that encourage youth to incorporate CM into their diets may help establish it as a component of habitual diet across their lifespans, and also represent an opportunity for "cradle-to-grave" branding for CM producers, which has proved successful for fast-food restaurant chains that use farmed meat.

A limitation of our study is that we measured participants' intention to consume CM and not their actual behavior. While intention is not a perfect indicator of behavior, the theory of planned behavior has shown that it is associated with action, including changing food intake (Ajzen, 1991). However, $\mathrm{CM}$ is not currently available commercially, and none of the participants have sampled it. This may result in CM being regarded as more "abstract" for participants and add additional uncertainty to the intention-behavior relationship. Another limitation is that we used a within subjects design whereby all participants received each of the messaging conditions, and we were not able to determine the specific effect of naturalness framing in the absence of the prior educational messaging on the benefits of CM. It would be of interest in further studies to assess to what extent perceptions of CM might vary with the type of cattle farming used for comparison (for instance, factory-farmed vs. grass-fed free-range). Finally, while our cohort was intended to be a convenience sample of college-aged Canadians, it may not be representative of the wider population of young adults with respect to sociodemographic and belief characteristics, and our sample size is limited. For instance, the influence of gender on attitudes toward CM and responses to messaging is of interest and could be explored with a larger and more representative sample in the future.

\section{CONCLUDING REMARKS}

The Masson-Delmotte et al. (2018) has concluded we have $<12$ years to limit the effects of climate change and prevent catastrophic warming and associated impacts from occurring. Our current intensive animal agriculture system is not sustainable, and alternate production approaches are required (Tilman et al., 2002). Sustainable Development Goal 12 focuses on building sustainable consumption and production patterns across the globe (United Nations, 2015), and CM could make a significant contribution to this. This study contributes to our understanding of the psychological barriers to consumer acceptance of CM, with a focus on youth for the first time. Our results show that youth generally have positive attitudes toward CM and see personal benefit in consuming it. However, many are not willing to spend more money on the product compared to traditionally sourced meat and have concerns about its potential taste, informing pricing and production practices, respectively. Youth believe $\mathrm{CM}$ to be unnatural, but ethical and environmentally friendly. While food disgust is negatively associated with CM, it did not affect behavioral intent, suggesting that it is not a barrier to acceptance. Further, we show for the first time with youth that educational and naturalness messaging can be effective tools to increase intent to consume CM and incorporate it into diets; a finding that is robust across the value, attitude and psychological factors examined. Taken overall, our study provides actionable information for both CM producers and marketers and assists in the transition to a more sustainable food system.

\section{DATA AVAILABILITY STATEMENT}

The datasets generated for this study are available on request to the corresponding author.

\section{ETHICS STATEMENT}

The studies involving human participants were reviewed and approved by Brock University Research Ethics Board (File 
\#18-036). The patients/participants provided their written informed consent to participate in this study.

\section{AUTHOR CONTRIBUTIONS}

SR collected the data and wrote the draft version of this manuscript. GP revised and edited the manuscript. SR and GP both contributed to the conception and design of the study. All authors contributed to the article and approved the submitted version.

\section{FUNDING}

A Social Sciences and Humanities Research Council of Canada Insight Development Grant (\#430-2019-01126) to GP providing funding support for this project, including

\section{REFERENCES}

Ajzen, I. (1991). The theory of planned behavior. Organ. Behav. Hum. Decis. Process 50, 179-211. doi: 10.1016/0749-5978(91)90020-T

Allievi, A, Vinnari, M. and Luukkanen, J. (2015). Meat consumption and production - analysis of efficiency, sufficiency and consistency of global trends. J. Clean. Prod. 92, 142-151. doi: 10.1016/j.jclepro.2014.12.075

Anderson, J., and Bryant, C. (2018). Messages to Overcome Naturalness Concerns in Clean Meat Acceptance: Primary Findings. Faunalytics.

Asensio, O. I., and Delmas, M. A. (2016). The dynamics of behavior change: evidence from energy conservation. J. Econ. Behav. Organ. 126, 196-212. doi: 10.1016/j.jebo.2016.03.012

Bhat, Z. F., Kumar, S., and Bhat, H. F. (2017). In vitro meat: a future animal-free harvest. Crit. Rev. Food Sci. Nutr. 57, 782-789. doi: 10.1080/10408398.2014.924899

Bourassa, L. (2019). Vegan and Plant-Based Diet Statistics. Available online at: https://plantproteins.co/vegan-plant-based-diet-statistics/ (accessed June 11, 2020).

Bryant, C., and Barnett, J. (2018). Consumer acceptance of cultured meat: a systematic review. Meat Sci. 143, 8-17. doi: 10.1016/j.meatsci.2018.04.008

Commissioner (2018). Statement From USDA Secretary Perdue and FDA Commissioner Gottlieb on the Regulation of Cell-Cultured Food Products From Cell Lines of Livestock and Poultry [WebContent]. Available online at: https:// www.fda.gov/NewsEvents/Newsroom/PressAnnouncements/ucm626117.htm (accessed January 02, 2019).

Delgado, C. L. (2003). Rising consumption of meat and milk in developing countries has created a new food revolution. J. Nutr. 133, 3907S-3910S. doi: $10.1093 / \mathrm{jn} / 133.11 .3907 \mathrm{~S}$

Devine, C. M. (2005). A life course perspective: understanding food choices in time, social location, and history. J. Nutr. Educ. Behav. 37, 121-128. doi: 10.1016/S1499-4046(06)60266-2

Druckman, J. N. (2001). Using credible advice to overcome framing effects. J. Law Econ. Org. 17, 62-82. doi: 10.1093/jleo/17.1.62

Dunlap, R. E., and Van Liere, K. D. (1978). The "new environmental paradigm": a proposed measuring instrument and preliminary results. J. Environ. Educ. 9, 10-19. doi: 10.1080/00958964.1978.10801875

Egolf, A., Siegrist, M., Ammann, J., Pacheco-Lópezb, G., Etale, A., and Hartmann, C. (2019). Cross-cultural validation of the short version of the food disgust scale in ten countries. Appetite 143:104420. doi: 10.1016/j.appet.2019.104420

Egolf, A., Siegrist, M., and Hartmann, C. (2018). How people's food disgust sensitivity shapes their eating and food behaviour. Appetite 127, 28-36. doi: 10.1016/j.appet.2018.04.014

FAO (2006). The state of Food Insecurity in the World. Food and Agriculture Organization of the United Nations. Available online at: http://www.fao.org/3/ a0750e/a0750e00.htm (accessed July 31, 2020).

Ferguson, L. R. (2010). Meat and cancer. Meat Sci. 84, 308-313. doi: 10.1016/j.meatsci.2009.06.032 publication costs. The Brock University Library subsidized publication costs.

\section{ACKNOWLEDGMENTS}

Thank you to all our study participants, Hannah Pickering from Brock University for technical assistance, and the Social Sciences and Humanities Research Council of Canada for funding to GP. Thank you also to the reviewers whose comments have helped to improve the paper significantly.

\section{SUPPLEMENTARY MATERIAL}

The Supplementary Material for this article can be found online at: https://www.frontiersin.org/articles/10.3389/fsufs. 2020.00122/full\#supplementary-material

Fortune Business Insights (2019). Meat Substitute Market Size, Share and Growth Report 2026. Retrieved from: https://www.fortunebusinessinsights. com/industry-reports/meat-substitutes-market-100239 (accessed May 18, 2020).

Gifford, K., and Bernard, J. C. (2006). Influencing consumer purchase likelihood of organic food. Int. J. Consum. Stud. 30, 155-163. doi: 10.1111/j.1470-6431.2005.00472.x

Goldstein, N. J., Cialdini, R. B., and Griskevicius, V. (2008). A room with a viewpoint: using social norms to motivate environmental conservation in hotels. J. Consum. Res. 35, 472-482. doi: 10.1086/586910

Goodwin, J. N., and Shoulders, C. W. (2013). The future of meat: a qualitative analysis of cultured meat media coverage. Meat Sci. 95, 445-450. doi: 10.1016/j.meatsci.2013.05.027

Grunert, K. G., Bredahl, L., and Brunsø, K. (2004). Consumer perception of meat quality and implications for product development in the meat sector-a review. Meat Sci. 66, 259-272. doi: 10.1016/S0309-1740(03)00130-X

Hartmann, C., and Siegrist, M. (2017). Consumer perception and behaviour regarding sustainable protein consumption: a systematic review. Trends Food Sci. Technol. 61, 11-25. doi: 10.1016/j.tifs.2016.12.006

Hartmann, C., and Siegrist, M. (2018). Development and validation of the food disgust scale. Food Qual. Prefer. 63, 38-50. doi: 10.1016/j.foodqual.2017.07.013

Hoek, A. C., Luning, P. A., Weijzen, P., Engels, W., Kok, F. J., and de Graaf, C. (2011). Replacement of meat by meat substitutes. A survey on personand product-related factors in consumer acceptance. Appetite 56, 662-673. doi: 10.1016/j.appet.2011.02.001

Hurlstone, M. J., Lewandowsky, S., Newell, B. R., and Sewell, B. (2014). The effect of framing and normative messages in building support for climate policies. PLoS ONE 9:e114335. doi: 10.1371/journal.pone.0114335

Laestadius, L. I., and Caldwell, M. A. (2015). Is the future of meat palatable? Perceptions of in vitro meat as evidenced by online news comments. Public Health Nutr. 18, 2457-2467. doi: 10.1017/S1368980015000622

Lake, A. A., Mathers, J. C., Rugg-Gunn, A. J., and Adamson, A. J. (2006). Longitudinal change in food habits between adolescence (11-12 years) and adulthood (32-33 years): the ASH30 study. J. Public Health 28, 10-16. doi: $10.1093 /$ pubmed/fdi082

Lynch, J., and Pierrehumbert, R. (2019) Climate impacts of cultured meat and beef cattle. Front. Sustain. Food Syst. 3:5. doi: 10.3389/fsufs.2019.00005

Masson-Delmotte, V., Zhai, P., Portner, H., Roberts, D., Skea, J., Shukla, P. et al. (2018). IPCC, 2018: Global Warming of $1.5^{\circ} \mathrm{C}$. An IPCC Special Report on the Impacts of Global Warming of $1.5^{\circ} \mathrm{C}$ Above Pre-industrial Levels and Related Global Greenhouse Gas Emission Pathways, in the Context of Strengthening Global Response to the Threat of Climate Change, Sustainable Development, and Efforts to Eradicate Poverty. Intergovernmental Panel on Climate Change.

Mayo Clinic (2019). Vegetarian Diet: How to Get the Best Nutrition. Available online at: https://www.mayoclinic.org/healthy-lifestyle/nutritionand-healthy-eating/in-depth/vegetarian-diet/art-20046446 (accessed June 11, 2020). 
Montgomery, K. C., and Chester, J. (2009). Interactive food and beverage marketing: targeting adolescents in the digital age. J. Adolesc. Health 45, S18-S29. doi: 10.1016/j.jadohealth.2009.04.006

Morris, S., and Pickering, G. J. (2019). Visual representations of climate changea case study of Canada. J. Environ. Soc. Sci. 6, 1-11. Available online at: https://www.opensciencepublications.com/fulltextarticles/ESS-2454-59536-139.html

Movassagh, E. Z., Baxter-Jones, A. D. G., Kontulainen, S., Whiting, S. J., and Vatanparast, H. (2017). Tracking dietary patterns over 20 years from childhood through adolescence into young adulthood: the saskatchewan pediatric bone mineral accrual study. Nutrients 9:990. doi: 10.3390/nu9090990

Munoz-Carrier, G., Thomsen, D., and Pickering, G. J. (2020). Psychological and experiential factors affecting climate change perception: learnings from a transnational empirical study and implications for framing climate-related flood events. Environ. Res. Commun. 2:045003. doi: 10.1088/2515-7620/ab89f9

Pickering, G. (2015). Head in the (oil) sand? climate change scepticism in Canada. Environ. Soc. Sci. 2, 1-11.

Pickering, G. J., Pickering, H. M. G., Northcotte, A., and Habermebl, C. (2020). Participation in residential organic waste diversion programs: motivators and optimizing educational messaging. Resour. Conserv. Recycl. 158:104807. doi: 10.1016/j.resconrec.2020.104807

Pickering, G. J., Schoen, K., Botta, M., and Fazio, X. (in press). Exploration of youth knowledge and perceptions of individual-level climate mitigation action. Environ. Res. Lett.

Pliner, P. (1982). The effects of mere exposure on liking for edible substances. Appetite 3, 283-290. doi: 10.1016/S0195-6663(82)80026-3

Pliner, P., and Hobden, K. (1992). Development of a scale to measure the trait of food neophobia in humans. Appetite 19, 105-120. doi: 10.1016/0195-6663(92)90014-W

Post, M. (2012). Cultured meat from stem cells: challenges and prospects. Meat Sci. 92, 297-301. doi: 10.1016/j.meatsci.2012.04.008

Raudenbush, B., and Frank, R. A. (1999). Assessing food neophobia: the role of stimulus familiarity. Appetite 32, 261-271. doi: 10.1006/appe.1999.0229

Román, S., Sánchez-Siles, L. M., and Siegrist, M. (2017). The importance of food naturalness for consumers: results of a systematic review. Trends Food Sci. Technol. 67, 44-57. doi: 10.1016/j.tifs.2017.06.010

Ronteltap, A., Reinders, M. J., van Dijk, S. M., Heijting, S., van der Lans, I. A., and Lotz, L. A. P. (2016). How technology features influence public response to new agrifood technologies. J. Agric. Environ. Ethics 29, 643-672. doi: 10.1007/s10806-016-9625-8

Roos, E., Sundberg, C., Tidaker, P., Strid, I., and Hansson, P. (2013). Can carbon footprint serve as an indicator of the environmental impact of meat production? Ecol. Indic. 24, 573-581. doi: 10.1016/j.ecolind.2012.08.004

Rozin, P., Markwith, M., and Stoess, C. (1997). Moralization and becoming a vegetarian: the transformation of preferences into values and the recruitment of disgust. Psychol. Sci. 8, 67-73. doi: 10.1111/j.1467-9280.1997.tb00685.x

Ruble, R. A. (2017). "Experimental manipulation," in The SAGE Encyclopedia of Communication Research Methods, ed M. Allen (Thousand Islands: SAGE Publications Inc.).

Ruby, M. B. (2012). Vegetarianism. A blossoming field of study. Appetite 58, 141-150. doi: 10.1016/j.appet.2011.09.019

Siegrist, M. (2008). Factors influencing public acceptance of innovative food technologies and products. Trends Food Sci. Technol. 19, 603-608. doi: 10.1016/j.tifs.2008.01.017

Siegrist, M., and Sütterlin, B. (2017). Importance of perceived naturalness for acceptance of food additives and cultured meat. Appetite 113, 320-326. doi: 10.1016/j.appet.2017.03.019

Siegrist, M., Sütterlin, B., and Hartmann, C. (2018). Perceived naturalness and evoked disgust influence acceptance of cultured meat. Meat Sci. 139, 213-219. doi: 10.1016/j.meatsci.2018.02.007

Slade, P. (2018). If you build it, will they eat it? Consumer preferences for plant-based and cultured meat burgers. Appetite 125, 428-437. doi: 10.1016/j.appet.2018.02.030

Smith, S. M., and Petty, R. E. (1996). Message framing and persuasion: a message processing analysis. Pers. Soc. Psychol. Bull. 22, 257-268. doi: $10.1177 / 0146167296223004$

Statista (2018). Instagram: Active Users 2018. Statista. Available online at: https:// www.statista.com/statistics/253577/number-of-monthly-active-instagramusers/ (accessed May 05, 2020).
Stea, S., and Pickering, G. J. (2018). Optimizing messaging to reduce red meat consumption. Environ. Commun. 13, 633-648. doi: 10.1080/17524032.2017.1412994

Steinfeld, H., Gerber, P., Wassenaar, T. D., Castel, V., Rosales, M. M., De haan C. (2006). Livestock's Long Shadow: Environmental Issues and Options. Viale delle Terme di Caracalla: Food and Agriculture Organization of the United Nations.

Stephens, N., Di Silvio, L., Dunsford, I., Ellis, M., Glencross, A., and Sexton, A. (2018). Bringing cultured meat to market: technical, socio-political, and regulatory challenges in cellular agriculture. Trends Food Sci. Technol. 78, 155-166. doi: 10.1016/j.tifs.2018.04.010

Stevens, C. J. (2019). Nitrogen in the environment. Science 363, 578-580. doi: $10.1126 /$ science.aav8215

Thibodeau, M., Yang, Q., Ford, R., and Pickering, G. J. (in press). Validation and optimisation of the English version of the food disgust scale. J. Sens. Stud.

Tilman, D., Cassman, K. G., Matson, P. A., Naylor, R. and Polasky, S. (2002). Agricultural sustainability and intensive production practices. Nature 418, 671-677. doi: 10.1038/nature01014

Tuomisto, H. L., and Teixeira de Mattos, M. J. (2011). Environmental impacts of cultured meat production. Environ. Sci. Technol. 45, 6117-6123. doi: 10.1021/es200130u

Tuorila, H., Lähteenmäki, L., Pohjalainen, L., and Lotti, L. (2001). Food neophobia among the finns and related responses to familiar and unfamiliar foods. Food Qual. Prefer. 12, 29-37. doi: 10.1016/S0950-3293(00)00025-2

United Nations (2015). Sustainable Development Goals. Available online at: https:// sustainabledevelopment.un.org/?menu=1300 (accessed May 05, 2020).

van der Weele, C., and Driessen, C. (2019). How normal meat becomes stranger as cultured meat becomes more normal; ambivalence and ambiguity below the surface of behavior. Front. Sustain. Food Syst. 3:69. doi: 10.3389/fsufs.2019.00069

Verbeke, W., Marcu, A., Rutsaert, P., Gaspar, R., Seibt, B., Fletcher, D., et al. (2015a). 'Would you eat cultured meat?': consumers' reactions and attitude formation in Belgium, Portugal and the United Kingdom. Meat Sci. 102, 49-58. doi: 10.1016/j.meatsci.2014.11.013

Verbeke, W., Sans, P., and Van Loo, E. J. (2015b). Challenges and prospects for consumer acceptance of cultured meat. J. Integr. Agric. 14, 285-294. doi: 10.1016/S2095-3119(14)60884-4

Westhoek, H., Lesschen, J. P., Rood, T., Wagner, S., De Marco, A., Murphy-Bokern, D., Oenema, O. (2014). Food choices, health and environment: effects of cutting Europe's meat and dairy intake. Glob. Environ. Change-Hum. Policy Dimens. 26, 196-205. doi: 10.1016/j.gloenvcha.2014.02.004

Whitelock, E., and Ensaff, H. (2018). On your own: older adults' food choice and dietary habits. Nutrients 10:413. doi: 10.3390/nu10040413

Whitmarsh, L. (2011). Scepticism and uncertainty about climate change: dimensions, determinants and change over time. Glob. Environ. Change 21, 690-700. doi: 10.1016/j.gloenvcha.2011.01.016

Wilks, M., Phillips, C., Fielding, K., and Hornsey, M. (2019). Testing potential psychological predictors of attitudes towards cultured meat. Appetite 136, 137-145. doi: 10.1016/j.appet.2019.01.027

Youth Stats: Environment and Climate Change. (2015). Office of the SecretaryGeneral's Envoy on Youth. Youth Stats: Environment and Climate Change.

Youth and Climate Change (2010). United Nations Joint Framework Initiative on Children. Youth and Climate Change.

Zhong, V. W., Horn, L. V., Greenland, P., Carnethon, M. R., Ning, H., Wilkins, J. T., et al. (2020). Associatons of processed meat, unprocessed red meat, poultry, or fish intake with incident cardiovascular disease and all-cause mortality. JAMA Intern. Med. 180, 503-512. doi: 10.1001/jamainternmed. 2019.6969

Conflict of Interest: The authors declare that the research was conducted in the absence of any commercial or financial relationships that could be construed as a potential conflict of interest.

Copyright (c) 2020 Ruzgys and Pickering. This is an open-access article distributed under the terms of the Creative Commons Attribution License (CC BY). The use, distribution or reproduction in other forums is permitted, provided the original author(s) and the copyright owner(s) are credited and that the original publication in this journal is cited, in accordance with accepted academic practice. No use, distribution or reproduction is permitted which does not comply with these terms. 